management. <https://www.uptodate.com/content s/basic-principles-of-wound-management>.

3. Spear M. and Bailey A. (2009). Treatment of Skin Graft Donor Sites With a Unique Transparent Absorbent Acrylic Dressing. Plastic Surgical Nursing, 29(4).

4. Bộ $Y$ tế Phiếu khảo sát người bệnh nội trú. $<$ http://kcb.vn/wpcontent/uploads/2016/11/Phieu-1_H\%C3\%A0i1\%C3\%B2ng-ng\%C6\%B0\%E1\%BB\%9Di-
b\%E1\%BB\%87nh-n\%E1\%BB\%99i-tr\%C3\%BA2016-pdf.pdf>

5. Gurtner G.C. Skin graft. Plastic Surgery: Principles. 4th, Elsevier.

6. Struk S., Correia N., Guenane Y., et al. (2018). Full-thickness skin grafts for lower leg defects coverage: Interest of postoperative immobilization. Ann Chir Plast Esthet, 63(3), 229-233.

7. Cancer research UK Melanoma skin cancer incidence statistics, .

\title{
NGHIÊN CỨU ĐĂC ĐIỂM LÂM SÀNG VÀ KẾT QUẢ PHỐI HỢP ĐIỀU TRI TẠI CHỖ BÊ̂NH ZONA BẰNG MEDLO TẠI PHÒNG KHÁM CHUYÊN KHOA DA LIỄU FOB CẦN THO' NĂM 2020 - 2021
}

\author{
Trần Ngọc Sĩ ***, Huỳnh Như Huỳnh*, Nguyễn Văn Nguyên**, \\ Huỳnh Hùng Anh*, Huỳnh Bạch Cúc*, Huỳnh Văn Bá*
}

\section{TÓM TẮT}

Mục tiêu: Nghiên cứu đă̆c điểm lâm sàng và kết quả phối hợp điều trị tại chỗ bệnh zona bằng Medlo tại Phòng khám chuyên khoa Da liễu FOB Cần Thơ năm 2020 - 2021. Đối tượng và phương pháp: Nghiên cứu hàng loạt ca trên 50 bệnh nhân mắc bệnh zona điều trị ngoại trú tại Phòng khám Da liễu FOB Cần Thơ năm 2020 - 2021. Kết quả: Bệnh gặp ở mọi lứa tuổi, nhóm tuổi trên 60 tuổi thường gặp nhất (chiếm 48,98\%), thấp nhất là nhóm <15 tuổi (chiếm $6,12 \%)$. Tiền triệu: Nhóm đau nhức chiếm tỷ lệ cao nhất $(77,55 \%)$, kế đến là nhóm nóng rát $(53,06)$, thấp nhất là nhóm các triệu chứng khác $(2,04 \%)$. Điều trị trước khi khám: Nhóm chưa điều trị chiếm tỷ lệ cao nhất $(51,02 \%)$, kế đến là nhóm điêu trị không chuyên khoa da liễu $(24,49)$, thấp nhất là nhóm điều tri khoán $(10,2 \%)$. Thương tôn hồng ban chiếm tỷ lệ cao nhất $(93,88 \%)$, kế đển là mụn nước, bóng nước $(79,59 \%)$, seo gặp rất ít $(6,12 \%)$. Vị trí sang thương gặp ở các vùng đâu mặt cổ và liên sườn ngực tay chiếm tỷ lệ cao nhất $(32,65 \%)$. Mức độ nhẹ chiếm tỷ lệ cao nhất $(48,98 \%)$, kế đến là nhóm mức độ nhẹ $(26,53 \%)$, thấp nhất là nhóm nặng (24,49\%). Sau 3 tuấn đâu tiên, có $100 \%$ bệnh nhân hài lòng với kết quả điều trị. Sau 7 ngày, có $60,47 \%$ bệnh đáp ứng tốt, $25,58 \%$ bênh đáp ứng khá, 13,95\% trung bình; sau 14 ngày, có $86,49 \%$ bệnh đáp ứng tốt, $10,81 \%$ bệnh đáp ứng khá, $10,81 \%$ trung bình; sau 21 ngày, có $89,19 \%$ bênh đáp ứng tốt, $8,11 \%$ bệnh đáp ứng khá, 10,81\% bểnh trung bình. Qua các tuần điều trị không ghi nhận bất kì tác dụng không mong muốn nào. Kểt luận: Thương tổn mụn nước, bóng nước gặp ở hầu hết các

*Trường Đại học Y Dược Cần Thơ

**TT GD Nghề nghiệp Thẩm mỹ FOB

***Viên Thẩm mỹ Quốc Tế $A$ \&A

Chịu trách nhiệm chính: Huỳnh Văn Bá

Email: bs.ba_fob@yahoo.com.vn

Ngày nhận bài: 29/4/2021

Ngày phản biên khoa hoc: 23/5/2021

Ngày duyệt bài: $21 / 6 / 2021$ bệnh nhân. Mụn nước, bóng nước võ có nguy cơ bội nhiễm cao, cân lưu ý vấn đề đề phòng bội nhiễm trên các bệnh nhân nổi mụn nước, bóng nước. Sau quá trình điều trị bằng thuốc uống kết hợp thuốc bôi tại chỗ bằng Medlo cho kết quả điêuu trị tốt, thuốc bôi tại chỗ không ghi nhận tác dụng phụ.

Tư khóa: Bệnh zona, đặc điểm lâm sàng, kết quả điều trị, Medlo.

\section{SUMMARY}

\section{RESEARCH ON CLINICAL}

CHARACTERISTICS AND OUTCOMES OF HERPES ZOSTER BY COMBINATION WITH MEDLO AS A TOPICAL THERAPY AT FOB DERMATOLOGY CLINIC IN 2020 - 2021

Objectives: Studying clinical characteristics and outcome of shingles by combination with medlo as a topical therapy at FOB Dermatology Clinic in 2020 2021. Methods: Series cases study on 50 patients with shingles treated as outpatients at FOB Dermatology Clinic in 2020-2021. Results: The disease was found in all ages, $\geq 60$ year-old group was the most common (accounting for $48.98 \%$ ), The lowest percentage is the $<15$ year-old group (accounting for $6.12 \%$ ). The group of pain accounted for the highest rate $(77.55 \%)$, followed by the burning group (53.06), the lowest was the group of other symptoms $(2.04 \%)$. Treatment before examination: the group of untreated patients accounted for the highest rate $(51.02 \%)$, followed by the nondermatological treatment group (24.49\%), the lowest was folk methods (non-scientific treament) (10.2\%). Erythema lesions accounted for the highest percentage $(93.88 \%)$, followed by vesicles, bullae $(79.59 \%)$, and very few scars $(6.12 \%)$. The location of the lesion was found in the head, face, neck and intercostal areas, accounting for the highest percentage $(32.65 \%)$. The mild level accounted for the highest rate $(48.98 \%)$, followed by the mild group $(26.53 \%)$, the lowest was the severe group (24.49\%). After the first 3 weeks, $100 \%$ of patients are satisfied with the treatment results. After 7 days, $60.47 \%$ of 
patients responded excellently, $25.58 \%$ of patients responded well and $13.95 \%$ of patients had moderate response. After 14 days, $86.49 \%$ of patients responded excellently, $10.81 \%$ of patients responded well and $10.81 \%$ of patients had moderate response. After 21 days, $89.19 \%$ of patients responded excellently, $8.11 \%$ of patients responded well and $10.81 \%$ of patients had moderate respons. Over weeks of treatment, no adverse drug reactions were noted. Conclusion: Vesicles and bullae were found in most of the patients. Blisters, broken blisters have a high risk of superinfection, it is necessary to pay attention to the problem of superinfection in patients with blisters and blisters. After the course of treatment with oral drugs combined with topical drugs with Medlo gave excellent treatment results. There is no side effect recorded for topical therapy.

Keywords; Shingles, clinical features, outcome, Medlo.

\section{I. ĐăT VẤN ĐỀ}

Bệnh zona hay herpes zoster là bênh nhiễm trùng da cấp tính với biểu hiện là các ban đỏ, mụn nước, bóng nước tập trung thành đám, thành chùm dọc theo đường phân bố của thần kinh ngoại biên. Qua ba giai đoạn tiền triệu, toàn phát và sau zona đều có thể gặp triệu chứng đau tuy nhiên mỗi giai đoạn đó đều có những đăc điểm lâm sàng và mức độ đau khác nhau [3]. Các biến chứng có thể là da liễu (ví dụ: nhiễm khuẩn thứ cấp), thần kinh (ví dụ: đau dài hạn, liệt phân đoạn, đột quy.), nhãn khoa (ví dụ viêm giác mạc, viêm mống mắt, viêm nhãn áp thứ phát) hoặc viêm nội tạng (ví dụ viêm phổi) [6]. Ở Mỹ, gần $100 \%$ người lớn có chứng cứ huyết thanh về việc nhiễm varicella và đều có nguy cơ bị zona [7]. Ở nước ta, bệnh zona chiếm $41,53 \%$ tổng số bệnh da do virus và chiếm 5,33\% tổng các bệnh da điều trị nội trú tại Viện Da liễu Quốc gia [5].

$\mathrm{HZ}$ và các biến chứng của nó (đặc biệt là đau dây thần kinh) tạo ra gánh nặng đáng kể cho bệnh nhân, người chăm sóc, hể thống chăm sóc sức khỏe và người sử dụng lao động. Phòng ngừa và điều trị các biến chứng $\mathrm{HZ}$ vẫn là một thách thức điều trị mặc dù những tiến bộ của khoa học kỹ thuật gần đây. Do đó, chúng tôi thực hiển nghiên cứu "Nghiên cứu đặc điểm lâm sàng và kết quả phối hợp điều trị tại chố bênh zona bằng Medlo tại Phòng khám chuyên khoa Da liễu FOB Cần Thơ năm 2020 - 2021"với hai mục tiêu:

- Mô tả đặc điểm lâm sàng bênh zona tại Phòng khám chuyên khoa Da liễu FOB Cần Tho năm 2020 - 2021

- Nhận xét kết quả phối hợp điều trị tại chố bệnh zona bằng Medlo tại Phòng khám chuyên khoa Da liễu FOB Cần Thơ năm 2020 - 2021

\section{II. ĐỐI TƯợNG VÀ PHƯƠNG PHÁP NGHIÊN CỨU}

1. Đối tượng nghiên cứu: 50 bệnh nhân được chẩn đoán xác định bệnh zona, điều trị tai Phòng khám Da liễu FOB Cần Thơ năm 2020- 2021.

Tiêu chuẩn chọn: Chủ yếu dựa vào lâm sàng

- Bệnh nhân được chẩn đoán bệnh zona

- Bệnh nhân đồng ý tham gia nghiên cứu.

Tiêu chuẩn loại trừ: Bệnh nhân mắc các bệnh lí tâm thần. Bệnh nhân không đồng ý tham gia nghiên cứu. Bệnh nhân không thực hiện đầy đủ phác đồ điều trị. Bệnh nhân có bệnh lí tim mạch nặng, suy gan, suy thận.

\section{Phương pháp nghiên cứu}

Thiết kế nghiên cứu: Nghiên cứu hàng loạt ca Vật liệu nghiên cứu

- Sản phẩm MEDLO

- Thành phần: Glycerin, Acid boric, Gluconolacton, nước tinh khiết vừa đủ.

- Công dụng: Chăm sóc làm dịu da, làm khô tổn thương rì dịch.

- Cách sử dụng: Phun sương hoặc đắp ngày 3-4 lần lên vùng da có nhu cầu.

TC: 071.B.051.15; SPTN: 016/16/CBMP-CT

Sản xuất: Công ty TNHH mỹ phẩm Hồng Nhung

Địa chỉ: 14/14 Lý Tự Trọng, P. An Cư, Q. Ninh Kiều, TP. Cần Thơ.

Thời gian theo dõi kết quả điêu trị: 1 tuần, 2 tuâan, 3 tuần.

Xử lý số liệu: Bằng phần mềm SPSS 20.0

\section{KẾT QUẢ NGHIÊN CỨU}

\section{Tuổi của đối tượng nghiên cứu}

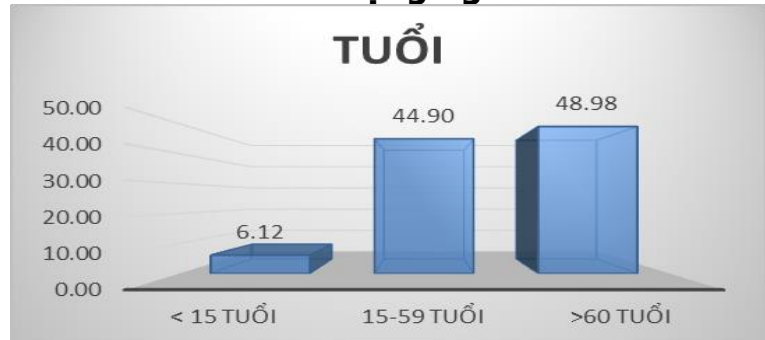

Nhận xét: Bệnh gặp ở mọi lứa tuổi, tuy nhiên nhóm tuổi trên 60 tuổi thường gặp nhất (chiếm 48,98\%), tỉ lệ thấp nhất là nhóm <15 tuổi (chiếm 6,12\%).

\section{Tiên triệu}

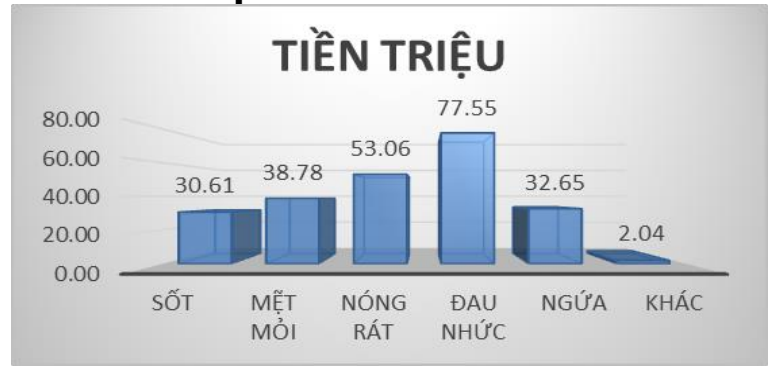


Nhân xét: Nhóm đau nhức chiếm tỷ lệ cao nhất $(77,55 \%)$, kễ đến là nhóm nóng rát $(53,06)$.

\section{3. Điêuu trị trước khi đến khám}

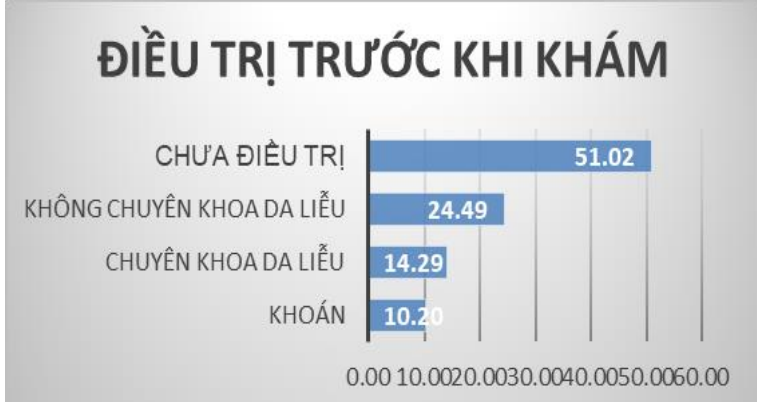

Nhận xét: Nhóm chưa điều trị chiếm tỷ lệ cao nhất $(51,02 \%)$, kế đến là nhóm điều trị không chuyên khoa da liễu $(24,49 \%)$, thấp nhất là nhóm điêu trị "khoán" (10,2\%).

\section{Thương tổn cơ bản}

\section{THƯƠNG TỔN CƠ BẢN}

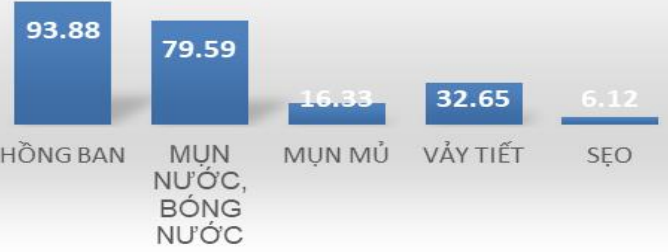

Nhận xét: Hồng ban gặp ở hầu hết các bênh nhân $(93,88 \%)$, kế đến là mụn nước, bóng nước (79,59\%), sẹo gặp rất ít (6,12\%).

5. Vị trí thương tổn

\section{V!̣ TRÍ TỔN THƯƠNG}

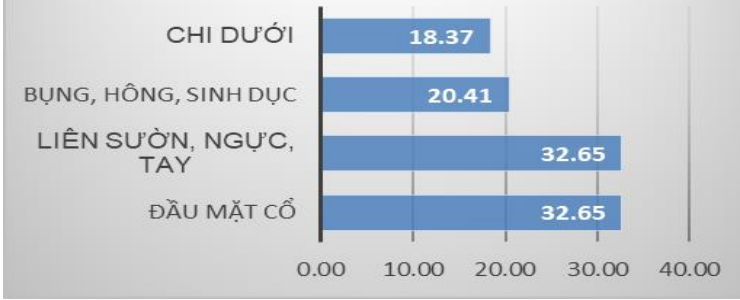

Nhận xét: Nhóm đầu mặt cổ và liên sườn ngực tay chiếm tỷ lệ cao nhất $(32,65 \%)$, thấp nhất là chi dưới (18,37\%).

6. Mức độ nặng của bệnh

\section{Mức độ bệnh}

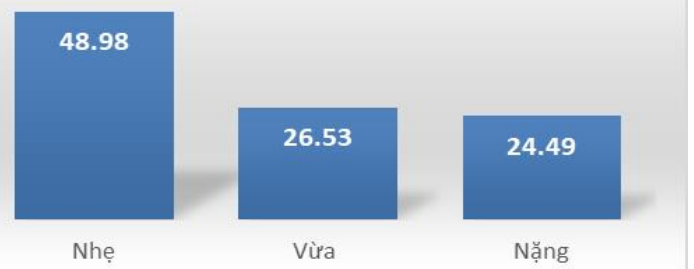

Nhận xét: Mức độ nhẹ chiếm tỷ lệ cao nhất $(48,98 \%)$, kế đến là nhóm mức độ vừa $(26,53 \%)$, thấp nhất là nhóm nặng $(24,49 \%)$.

7. Cảm nhận sự hài lòng của bệnh nhân sau điêu trị

CẢM NHẬN SAU ĐIỀU TR!

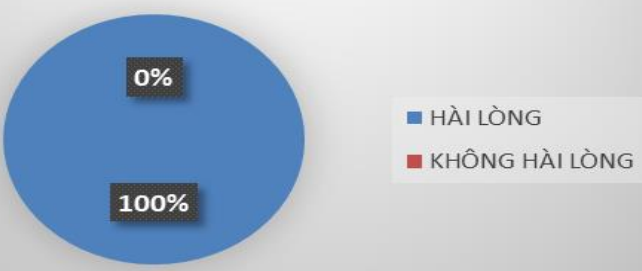

Nhận xét: Sau tuần đầu tiên, có 100\% bệnh nhân hài lòng với kết quả điều trị. Kết quả duy trì qua các tuần.

\section{8. Đánh giá kết quả điêu tri}

Kết quả sau thời gian điêu trị. Sau 7 ngày, có $60,47 \%$ bệnh đáp ứng tốt, $25,58 \%$ bệnh đáp ứng khá, 13,95\% trung bình. Sau 14 ngày, có $86,49 \%$ bệnh đáp ứng tốt, $10,81 \%$ bệnh đáp ứng khá, $10,81 \%$ trung bình. Sau 21 ngày, có $89,19 \%$ bệnh đáp ứng tốt, $8,11 \%$ bệnh đáp ứng khá, 10,81\% bệnh trung bình.

Mối liên quan giữa số lân đắp thuốc tại chỗ và đáp ứng điêu trị

\begin{tabular}{|c|c|c|c|c|c|c|c|c|c|c|}
\hline & \multicolumn{3}{|c|}{ Đáp ứng sau 7 ngày } & \multicolumn{3}{|c|}{ Đáp ứng sau 14 ngày } & \multicolumn{3}{|c|}{ Đáp ứng sau 21 ngày } \\
\hline & & Tốt & Khá & $\begin{array}{l}\text { Trung } \\
\text { bình }\end{array}$ & Tốt & Khá & $\begin{array}{c}\text { Trung } \\
\text { bình }\end{array}$ & Tốt & Khá & $\begin{array}{c}\text { Trung } \\
\text { bình }\end{array}$ \\
\hline \multirow{2}{*}{$\begin{array}{l}\text { Số lần } \\
\text { đắp } \\
\text { thuốc }\end{array}$} & $<3$ lần & $4,60 \%$ & $4,60 \%$ & $4,60 \%$ & $10,80 \%$ & $2,70 \%$ & $2,70 \%$ & $10,80 \%$ & $2,70 \%$ & $2,70 \%$ \\
\hline & $\geq 3$ lần & $55,80 \%$ & $2,10 \%$ & $9,30 \%$ & $75,70 \%$ & $8,10 \%$ & $0 \%$ & $78,40 \%$ & $5,40 \%$ & $0 \%$ \\
\hline
\end{tabular}

Nhận xét: Kết quả tỉ lệ đáp ứng điều trị tốt ở nhóm đắp thuốc $>3$ lần/ngày cao hơn nhóm đắp thuốc < 3 lần/ngày. Tuy nhiên, sự khác biệt không có ý nghĩa thống kê ( $p>0.05$ ). 
9. Tác dụng không mong muốn

\begin{tabular}{|c|c|c|c|}
\hline Tác dụng phụ & $\begin{array}{c}\mathbf{7} \\
\text { ngày }\end{array}$ & $\begin{array}{c}\mathbf{1 4} \\
\text { ngày }\end{array}$ & $\begin{array}{c}\mathbf{2 1} \\
\text { ngày }\end{array}$ \\
\hline Ngứa da & Không & Không & Không \\
\hline Đỏ da & Không & Không & Không \\
\hline Nóng rát tại chô̂ & Không & Không & Không \\
\hline Phát ban, mày đay & Không & Không & Không \\
\hline Khác & Không & Không & Không \\
\hline
\end{tabular}

Nhận xét: Qua các tuần điều trị không ghi nhận bất kì tác dụng không mong muốn nào.

\section{BÀN LUÂN}

1. Tuổi của đối tượng nghiên cứu. Bệnh zona gặp ở nhóm tuổi trên 60 tuổi thường nhất (chiếm 48,98\%), tỉ lệ thấp nhất là nhóm <15 tuổi (chiếm 6,12\%). Kết quả này phù hợp với kết quả nghiên cứu của Nguyễn Lan Anh, Đặng Văn Em (2015) ghi nhận tuổi trên 50 chiếm tỷ lệ cao nhất $80,8 \%$; trong đó tuổi trên 70 chiếm $31,08 \%$ [1], nghiên cứu của Nguyễn Thị Thu Hoài (2011), ghi nhận tuổi mắc bệnh thường gặp là trên $50(70,41 \%)$, trong đó có $22,53 \%$ bệnh nhân trên 70 tuổi [4].

2. Tiền triệu. Nhóm đau nhức chiếm tỷ lệ cao nhất $(77,55 \%)$, kế đến là nhóm nóng rát $(53,06)$, thấp nhất là nhóm các triệu chứng khác $(2,04 \%)$. Kết quả này tương đồng với kết quả nghiên cứu của Nguyến Lan Anh, Đặng Văn Em (2015) ghi nhận đau nhức gặp $81,9 \%$, rát $12,9 \%$ và ngứa $3,1 \%[1]$, nghiên cứu của Nguyễn Thị Thu Hoài (2011) [4].

3. Điêu trị trước khi đến khám. Nhóm chưa điều trị chiếm tỷ lệ cao nhất $(51,02 \%)$, kễ đến là nhóm điều trị khổng chuyên khoa da liễu $(24,49)$, thấp nhất là nhóm điều trị khoán $(10,2 \%)$. Việc tuyên truyền và nâng cao hiểu biết cả người dân về một số bệnh phổ biến đã thể hiện tầm quan trọng, chứng tỏ có hiệu quả bằng việc người bệnh đến khám bác sĩ chuyên khoa sớm và chiếm tỷ lệ cao.

4. Thương tổn cở bản: Hồng ban gặp ở hầu hết các bệnh nhân $(93,88 \%)$, kễ đển là mụn nước, bóng nước $(79,59 \%)$, sẹo gặp rất ít $(6,12 \%)$. Tỉ lệ này tương đương với tác giả Nguyễn Lan Anh, Đặng Văn Em (2015) ghi nhận mảng viêm đỏ nề gặp $100 \%$, mụn nước và phỏng nước $90,7 \%$, mụn mủ $25,9 \%$ và mụn máu 4,7\% [1], tác già Nguyễn Thị Thu Hoài (2011), hồng ban, mụn nước bóng nước chiếm tỷ lệ cao nhất [4].

5. Vị trí thương tổn. Trong nghiên cứu của chúng tôi, nhóm đầu mặt cổ và liên sườn ngực tay chiếm tỷ lệ cao nhất (32,65\%), thấp nhất là chi dưới $(18,37 \%)$. Kết quả này tương đương với tác giả Nguyễn Lan Anh, Đặng Văn Em (2015) ghi nhận liên sườn và đầu mặt cổ chiếm tỷ lệ cao nhất $(55,96 \% \%$ và $23,32 \%)$ [1], của tác giá Nguyễn Thị Thu Hoài (2011) liên sườn và đâu mặt cổ chiếm tỷ lệ cao nhất $(39,33 \%$ và $36,62 \%)$ [4].

6. Mức độ nặng của bệnh. Mức độ nhe chiếm tỷ lệ cao nhất (48,98\%), kễ đến là nhóm mức độ vừa $(26,53 \%)$, thấp nhất là nhóm nặng $(24,49 \%)$. Nghiên cứu của chúng tôi có sự không tương đồng với kết quả của tác giả Nguyển Lan Anh và Đặng Văn Em (2015), ghi nhận mức độ nặng chiếm tỷ lệ cao nhất $(55,4 \%)$, vừa $(24,4 \%)$, nhe $(6,2 \%)[1]$. Sự khác biệt này có thể do sự khác biệt về cõ mẫu.

7. Mức độ hài lòng của bệnh nhân sau điều trị: Sau tuần đầu tiên, có $100 \%$ bệnh nhân hài lòng với kết quả điều trị. Kết quả duy trì qua các tuần. Sự hài lòng của bệnh nhân dựa trên việc cải thiện các triệu chứng cơ năng, thực thể và tính thẩm mỹ khi sử dụng thuốc tại chố trong quá trình điều trị bệnh do bệnh nhân tự đánh giá.

8. Đánh giá kết quả điêuu trị. Sau 7 ngày, có $60,47 \%$ bệnh đáp ứng tốt, $25,58 \%$ bệnh đáp ứng khá, $13,95 \%$ trung bình. Sau 14 ngày, có $86,49 \%$ bệnh đáp ứng tốt, $10,81 \%$ bệnh đáp ứng khá, $10,81 \%$ trung bình. Sau 21 ngày, có $89,19 \%$ bệnh đáp ứng tốt, $8,11 \%$ bệnh đáp ứng khá, 10,81\% bệnh trung bình. Kết quả nghiên cứu của chúng tôi ghi nhận không có mối tương quan có ý nghãi thống kề giữa số lần đắp thuốc tại chố và đáp ứng điều trị ( $p>0.05)$. Theo kết quả nghiên cứu, không thấy mối tương quan giữa việc sử dụng thuốc bôi tại chỗ và đáp ứng điều trị. Tuy nhiên, sau 7 ngày điều trị, kết quả đáp ứng tốt ở nhóm đắp thuốc $\geq 3$ lần/ngày $(55,8 \%)$ chiếm tỷ lệ cao hơn rõ rệt so với đắp $<3$ lần/ngày $(4,6 \%)$. Điều này có thể gợi ý việc đắp thuốc nhiêu lần trong ngày cho kết quả điều trị tốt hơn. Do nghiên cứu của chúng tôi còn hạn chế về mẫu nên cần thêm nghiên cứu khác để chứng minh.

9. Tác dụng không mong muốn. Qua các tuần điều trị không ghi nhận bất kì tác dụng không mong muốn nào.

\section{KẾT LUẬN}

\section{1. Đặc điểm lâm sàng}

- Bệnh gặp ở mọi lứa tuổi, nhóm tuổi trên 60 tuổi thường gặp nhất (chiếm 48,98\%), tỉ lệ thấp nhất là nhóm <15 tuổi (chiếm 6,12\%).

- Tiền triệu: Nhóm đau nhức chiếm tỷ lệ cao nhất $(77,55 \%)$, kế đến là nhóm nóng rát $(53,06)$, thấp nhất là nhóm các triệu chứng khác (2,04\%). 
- Điều trị trước khi đến khám: Nhóm chưa điều trị chiếm tỷ lệ cao nhất $(51,02 \%)$ kế đến là nhóm điều trị không chuyên khoa da liểu $(24,49)$, thấp nhất là nhóm điều tri khoán $(10,2 \%)$.

- Thương tổn cơ bản: Hồng ban gặp ở hầu hết các bệnh nhân $(93,88 \%)$, kế đến là mụn nước, bóng nước (79,59\%), sẹo gặp rất ít (6,12\%).

- Vị trí thương tổn: Nhóm đầu mặt cổ và liên sườn ngực tay chiếm tỷ lệ cao nhất $(32,65 \%)$, thấp nhất là chi dưới (18,37\%).

\section{Kết quả điêuu trị}

- Trong quá trình điều trị, 100\% bệnh nhân hài lòng với kết quả điều trị.

- Kết quả điều trị: Sau 7 ngày, có 60,47\% bênh đáp ứng tốt, $25,58 \%$ bệnh đáp ứng trung bình, $13,95 \%$ kém. Sau 14 ngày, có $86,49 \%$ bệnh đáp ứng tốt, 10,81\% bệnh đáp ứng trung bình, 10,81\% kém. Sau 21 ngày, có $89,19 \%$ bệnh đáp ứng tốt, $8,11 \%$ bệnh đáp ứng trung bình, 10,81\% bệnh kém.

- Không ghi nhận tác dụng phụ nào.

TÀI LIỆ THAM KHẢO

1. Nguyễn Lan Anh, Đặng Văn Em (2015),
"Nghiên cứu một số đặc điểm dịch tễ và lâm sàng của bênh zona tại bệnh viện Trung ương Quân đội 108", Y hoc thực hành, 3 (953), tr.38-42.

2. Bộ Y tế (2015), "Bếnh zona", Hướng dẫn chẩn đoán và điêu tri các bểnh $\mathrm{Da}$ liễu, tr.67-71.

3. Tô Thị Thúy Hằng, võ Hồng Khôi (2018), "Đặc điểm đau trong bệnh zona theo thang điêm trực quan tương ứng (VAS)", Tạp chí y học Việt Nam, $1 \& 2$ (467), tr.100-103.

4. Nguyên Thị Thu Hoài (2011), "Mô tả một vài đặc điểm dị̣ch tê̂, lâm sàng bệnh zona điều trị tại khoa da liểu bênh viên đa khoa trung ương Thái nguyên và bệnh viện 103", Khoa học \& công nghệ, $112(12) / 2$, tr. $237-243$.

5. Đố Văn Khoát (1998), Nghiên cứu tình hình bệnh zona tai Viện Da liễu Việt Nam từ 19941998, Luân vằn thạc sỹ y học.

6. Kosuke Kawai , Barbara P Yawn, Peter Wollan et al (2016), "Increasing Incidence of Herpes Zoster Over a 60-year Period From a Population-based Study", Clin Infect Dis, 63 (2), pp.221-226.

7. Robert W. Johnson, Marie-José AlvarezPasquin, Marc Bijl et al (2015), "Herpes zoster epidemiology, management, and disease and economic burden in Europe: a multidisciplinary perspective", Ther Adv Vaccines, 3 (4), pp.109-120.

\section{HIỄU QUẢ ĐIỀU TRI ĐAU VÙNG CỔ GÁY DO THOÁI HÓA CộT SỐNG BĂNG BÀI THUỐC TAM TÝ THANG KẾT HỢP ĐIỆN CHÂM HUYÊTT GIÁP TÍCH CộT SỐNG Cổ}

\section{TÓM TẮT}

Mục tiêu: Đánh giá hiệu quả điều trị đau vùng cổ gáy do thoái hóa cột sốngbằng bài thuốc Tam tý thang kết hợp điện châm huyệt giáp tích cột sống cố. Đối tượng và̀ phướng pháp: 60 bểnh nhân tuổi từ 30 75 được chẩn đoán đau vùng cổ gáy do thoái hóa cột sống, không phân biêt giới tính, nghề nghiêp, tình nguyện tham gia nghiên cứu. Nhóm nghiên cứu điêu trị bẳng uống bài thuốc Tam tý thang kết hợp điện châm huyệt giáp tích cột sống cổ, nhóm đối chứng điều trị bằng điện châm huyệt giáp tích cột sống cổ đơn thuần. So sánh kết quả sau 14 ngày điều trị. Kết quả: bài thuốc Tam tý thang kết hợp điện châm huyệt giáp tích cột sống cổ hiệu quả trong điều trị đau vùng cổ gáy do thoái hóa cột sông, 96,7\% đạt hiệu quả tốt. Biên độ hoạt động cột sống cổ, mức độ đau và chức năng sinh hoạt hàng ngày NPQ cải thiện tốt hơn có ý

${ }^{1}$ Viện Y họ cổ truyền Quân đội,

ªểnh viện Châm cứu Trung ướng

Chịu trách nhiệm chính: Nguyễn Vinh Quốc

Email: quocnguyenvinh@gmail.com

Ngày nhân bài: 25/4/2021

Ngày phản biên khoa hoc: 25/5/2021

Ngày duyệt bài: 20/6/2021
Nguyễn Vinh Quốc ${ }^{1}$, Nguyễn Đức Minh ${ }^{2}$ nghĩa so với trước điều trị và tốt hơn so với nhóm đối chứng. Kết luận: bài thuốc Tam tý thang kết hợp điện châm huyệt giáp tích cột sống cổ hiệu quả tốt trong điêu trị đau vùng cổ gáy do thoái hóa cột sống.

Tư khóa: Đau vùng cổ gáy, huyệt giáp tích cột sống cổ, điện châm.

\section{SUMMARY}

THE EFFECT OF "TAM TY THANG" COMBINED WITH ELECTRO-ACUPUNCTUREAT CERVICAL JIAJI POINT ON TREATING NECK PAIN WITH CERVICAL SPONDYLOSIS

Objective: To evaluate effect of "Tam ty thang" withelectro-acupuncture at cerviacal Jiaji pointon treament of neck pain with cervical spondylosis. Subjects and methods: 60 volunteered patients aged from 30 to 75 diagnosed with neck pain with cervical spondylosis, regardless of gender or occupation, were participated in the study. Researchers combined using "Tam ty thang"withelectro-acupuncture at cerviacal Jiaji point, while the control group was treated by electroacupuncture at cerviacal Jiaji point. Comparing the results after 14 days treatment. Result: The spondylosis of neck pain with cervical spinetreating 